\title{
Glucose Tolerance and Smoking: A Population Study of Oral and Intravenous Glucose Tolerance Tests in Middle-Aged Men
}

\author{
L. Janzon ${ }^{1}$, K. Berntorp ${ }^{2}$, M. Hanson ${ }^{2}$, S.-E. Lindell ${ }^{3}$ and E.Trell ${ }^{4}$ \\ Departments of Surgery ${ }^{1}$, Internal Medicine ${ }^{2}$, Clinical Physiology ${ }^{3}$ and Preventive Medicine ${ }^{4}$, University of Lund and Malmö General Hospital, \\ Malmö, Sweden
}

\begin{abstract}
Summary. The oral and intravenous glucose tolerance tests have been compared in middle-aged, normal-weight male non-smokers, ex-smokers and smokers who participated in a general health screening programme in Malmö, Sweden. Subjects with diabetes, previous gastric resection and/or present medication with diuretic agents were excluded. No difference was found when comparing fasting glucose in non-smokers, ex-smokers and smokers. In the oral glucose tolerance test, plasma glucose at 40 and $60 \mathrm{~min}$ increased stepwise from nonsmokers $(8.7$ and $7.4 \mathrm{mmol} / \mathrm{l})$ to ex-smokers ( 8.9 and $7.5 \mathrm{mmol} / \mathrm{l})$, smokers (9.2 and $7.9 \mathrm{mmol} / \mathrm{l}$ ) and heavy smokers
\end{abstract}

( 9.7 and $8.2 \mathrm{mmol} / 1)$. Blood glucose levels at $120 \mathrm{~min}$ were inversely arranged. Plasma insulin at $120 \mathrm{~min}$ was lower in heavy smokers $(16.2 \mathrm{mU} / \mathrm{l})$ than in non-smokers $(24.8 \mathrm{mU} / \mathrm{l})$. The mean intravenous glucose tolerance test k-value was lower in smokers than in non-smokers. K-values below 1.0 were twice as common in smokers $(30 \%)$ as in non-smokers. It is concluded that smoking has a clinically significant influence on both the oral and intravenous glucose tolerance tests.

Key words: Smoking, glucose tolerance, plasma insulin.
The transient increase in blood glucose associated with smoking represents one of the many well known acute effects of nicotine [1]. So far little has been published on chronic effects of smoking on glucose metabolism. Our previous studies on the oral and intravenous glucose tolerance tests in middle-aged heavy smokers and nonsmokers [2-4] showed that heavy smokers have significantly higher glucose value during the early phase of the oral glucose tolerance test whereas their 2 -h value is significantly lower. The comparison of intravenous glucose tolerance test in smokers and non-smokers suggested that smoking is associated with a reduced clearance of glucose from plasma.

In order to explore further these associations, we have now extended our study to include non-smokers, ex-smokers, smokers and heavy smokers. Potential confounding factors have been controlled for by confining the study to middle-aged, non-diabetic, normal weight men without previous gastric resection and/or present medication with diuretic agents.

\section{Material and Methods}

From November 1974 consecutive middle-aged male birth cohorts in Malmö have been invited to take part in a general health screening programme at the Department of Preventive Medicine, Malmö General Hospital. Details of the programme have been published elsewhere [5]. The participation rate in these cohorts was about $75 \%$. The present study was confined to men born between 1926 and 1929. None had clinical or chemical signs of diabetes (ie fasting blood glucose $>7.0 \mathrm{mmol} / \mathrm{l})$. Subjects with a history of gastric resection and/or present medication with diuretic agents were excluded. Fur- thermore, the comparison was restricted to men with normal body weight (actual/ideal weight index between $0.95-1.05$ as calculated according to Lindeberg et al. [6].) The mean actual/ideal weight index was 1.0 in all groups studied.

All subjects were instructed to fast and to abstain from tobacco for $10 \mathrm{~h}$ before examination. Smoking abstinence was checked by questioning. Participants were randomly allocated to screening by oral and intravenous tolerance test (GTT) procedures. For the oral GTT, data were available on 325 non-smokers, 300 ex-smokers, 681 smokers and 148 heavy smokers. For the IV GTT data were available in 113 non-smokers, 71 ex-smokers, 193 smokers and 52 heavy smokers.

\section{Smoking Habits}

Smoking habits were assessed by questionnaire [7]. Categories were defined as follows: (1) non-smokers had never smoked regularly; (2) ex-smokers had smoked at least $1 \mathrm{~g}$ of tobacco daily for at least 1 year, but at the time of examination had not smoked for at least 1 month; (3) smokers smoked daily; (4) heavy smokers smoked at least $20 \mathrm{~g}$ of tobacco daily.

One cigarette was considered equal to $1 \mathrm{~g}$ of tobacco, 1 cigar to $5 \mathrm{~g}$ and one packet of pipe tobacco equal to $50 \mathrm{~g}$.

\section{Oral Glucose Tolerance Test}

Glucose $\left(30 \mathrm{~g} / \mathrm{m}^{2}\right.$ body area in $10 \%$ aqueous solution) was ingested within $10 \mathrm{~min}$. Blood glucose was measured at $0,40,60,90$ and $120 \mathrm{~min}$ by a standard method [8]. Plasma insulin immunoreactivity was determined in triplicate at 0,40 and $120 \mathrm{~min}$ by a radioimmunoassay technique [9].

\section{Intravenous Glucose Tolerance Test}

In the IV GTT, an intravenous catheter for repeated blood sampling was introduced into the left or right antecubital fossa and kept open by flushing with saline $0.9 \%$ after the sampling procedures. Glucose ( $25 \mathrm{~g} / \mathrm{m}^{2}$ body surface area in $40 \%$ sterile aqueous solution) was in- 
Table 1. The oral glucose tolerance test in middle-aged non-smokers, smokers and heavy smokers

\begin{tabular}{|c|c|c|c|c|c|}
\hline Group & Non-smokers $(n=325)$ & $\begin{array}{l}\mathrm{b} \\
\text { Ex-smokers }(n=300)\end{array}$ & $\begin{array}{l}c \\
\text { Smokers }(n=681)\end{array}$ & $\begin{array}{l}\mathrm{d} \\
\text { Heavy smokers }(n=148)\end{array}$ & $\begin{array}{l}\text { Significant } \\
\text { differences } \\
(p<0.05)^{\mathrm{a}}\end{array}$ \\
\hline \multicolumn{6}{|c|}{$\begin{array}{l}\text { Blood glucose } \\
(\mathrm{mmol} / 1)\end{array}$} \\
\hline $0 \mathrm{~min}$ & $4.7 \pm 1.32$ & $4.6 \pm 1.02$ & $4.6 \pm 0.96$ & $4.6 \pm 1.26$ & \\
\hline $40 \mathrm{~min}$ & $8.7 \pm 1.90$ & $8.9 \pm 2.13$ & $9.2 \pm 1.94$ & $9.7 \pm 2.00$ & $a-c, b-c, c-d$ \\
\hline $60 \mathrm{~min}$ & $7.4 \pm 1.99$ & $7.5 \pm 2.03$ & $7.9 \pm 2.3$ & $8.2 \pm 2.18$ & $a-c, b-c$ \\
\hline $90 \mathrm{~min}$ & $6.2 \pm 1.78$ & $6.3 \pm 1.73$ & $6.1 \pm 1.72$ & $6.2 \pm 1.93$ & \\
\hline $120 \mathrm{~min}$ & $5.5 \pm 1.67$ & $5.4 \pm 1.61$ & $4.9 \pm 1.39$ & $4.9 \pm 1.71$ & $a-c, b-c$ \\
\hline \multicolumn{6}{|c|}{ Insulin $(\mathrm{mU} / \mathrm{l})$} \\
\hline $0 \mathrm{~min}$ & 12.7 & 13.4 & 12.1 & 13.5 & \\
\hline $40 \mathrm{~min}$ & 66.7 & 72.0 & 67.3 & 73.3 & \\
\hline $120 \mathrm{~min}$ & 24.8 & 25.2 & 18.9 & 16.2 & $a-d$ \\
\hline
\end{tabular}

Results expressed as mean $\pm \mathrm{SD}$; insulin values represent median. ${ }^{\text {aAll }}$ other comparisons not significant

Table 2. The intravenous glucose tolerance test in middle-aged non-smokers, ex-smokers, smokers and heavy smokers

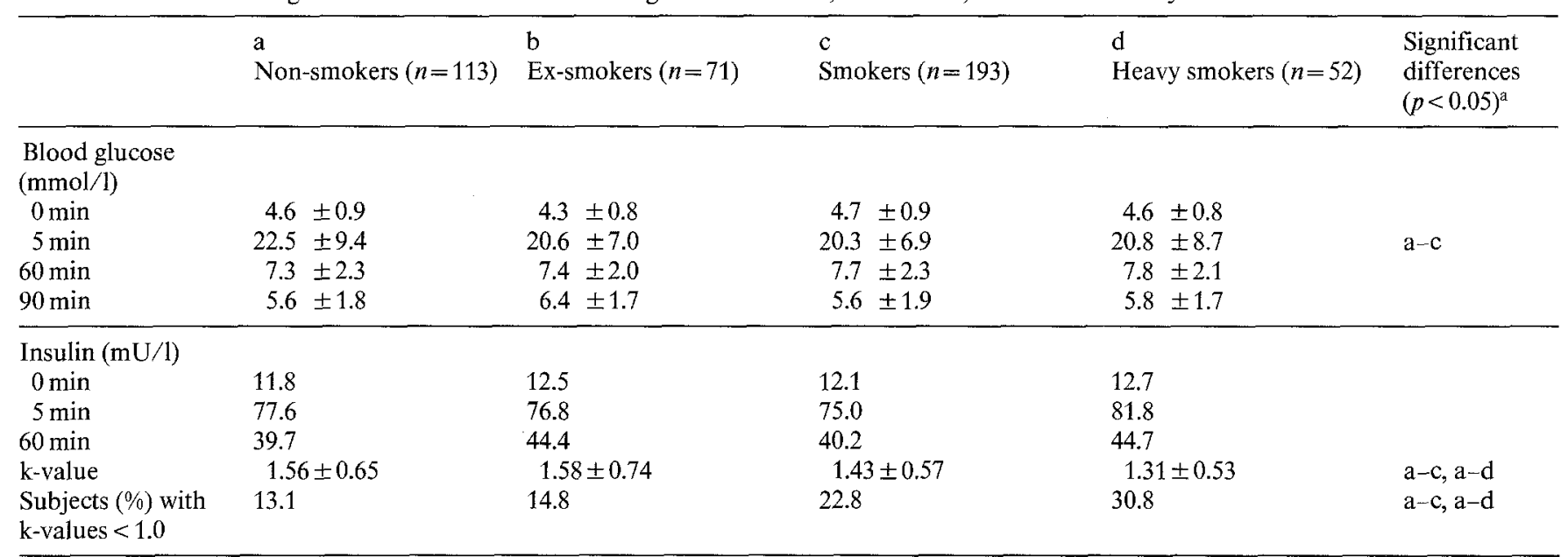

Results expressed as mean $\pm \mathrm{SD}$; insulin values represent median. ${ }^{a}$ All other comparisons not significant

jected at a constant rate over $3 \mathrm{~min}$. Blood glucose was measured at 0 , $5,20,30,40,50$ and $90 \mathrm{~min}$. Plasma insulin immunoreactivity was determined in triplicate at 0,5 and $60 \mathrm{~min}$. All glucose and insulin results were fed into a computer which automatically calculated the glucose disappearance constant, $\mathrm{k}$-value, according to the formula:

$K=-100 x\left(\frac{\Sigma(x y)-\frac{\Sigma x \Sigma y}{n}}{\Sigma x^{2}-\frac{(\Sigma x)^{2}}{n}}\right) \% / m i n$

$\mathrm{x}=$ time $(\mathrm{min}), \mathrm{y}=\log$ glucose $(\mathrm{mmol} / \mathrm{l})$

$n=$ number of measurements (number of $x$-values)

\section{Statistical Methods}

Student's t-test was used for comparison of mean blood glucose values in the four groups. The distribution of insulin was not normally distributed. For this reason, insulin values in the different smoking categories were compared using $\chi$-square on the $\mathrm{r} \times \mathrm{c}$ contingency table of frequencies within specified groups. $p$ values $<0.05$ were considered statistically significant.

\section{Results}

\section{Oral Glucose Tolerance Test}

Fasting blood glucose values were not signifiantly different in the four groups (Table 1). At $40 \mathrm{~min}$, the glu- cose concentration was higher in the smokers, (particularly the heavy smokers) than in non-smokers or ex-smokers. The same pattern was found at $60 \mathrm{~min}$. Mean glucose values at $90 \mathrm{~min}$ did not differ significantly between groups. At $120 \mathrm{~min}$, however, smokers had significantly lower values than did non-smokers and ex-smokers.

Fasting insulin values did not differ significantly between groups. At $40 \mathrm{~min}$, smokers and heavy smokers tended to have higher insulin values than non-smokers, but the difference did not reach statistical significance. At $120 \mathrm{~min}$, smokers and heavy smokers had lower insulin than non-smokers.

\section{Intravenous Glucose Tolerance Test}

As in the oral GTT, fasting values of glucose and insulin did not differ significantly between groups (Table 2). At $5 \mathrm{~min}$, blood glucose was lower in smokers than in nonsmokers. Plasma insulin values at $5 \mathrm{~min}$ and $60 \mathrm{~min}$ and glucose at 60 and $90 \mathrm{~min}$ were not significantly different in the four groups. The glucose disappearance constant (k-value) was significantly lower in smokers (particularly heavy smokers) than in non-smokers or ex-smok- 
ers. In the present screening, $k$-values above 1.0 were considered normal. K-values equal to or below 1.0 were observed in $31 \%$ of the heavy smokers, but only in $13 \%$ of the non-smokers and $15 \%$ of the ex-smokers.

\section{Discussion}

Invitations to screening were made in a random fashion and the same standardized screening procedure was used for all participants. Hence it is not possible to explain the observed differences between smokers and non-smokers on the basis of seasonal and/or methodological differences. Since all smokers had abstained from tobacco for at least $10 \mathrm{~h}$ before examination and since the half-life of nicotine is less than $1 \mathrm{~h} \mathrm{[10],} \mathrm{it} \mathrm{is}$ reasonable to assume that the observed influence of smoking on the oral and intravenous GTT represented the chronic effects of smoking. The high 40-min blood glucose value in the oral GTT might reflect a more rapid absorption from the intestine in smokers than in nonsmokers. It is less likely to reflect different dietary habits in these two groups [11] since the $40 \mathrm{~min}$ value increased stepwise when comparing non-smokers, exsmokers, smokers and heavy smokers. A difference between smokers and ex-smokers at 40,60 and $120 \mathrm{~min}$ indicated that the effect of smoking on the oral GTT was reversible. Although no difference was found when comparing the $120 \mathrm{~min}$ value in smokers and heavy smokers, it appears that the effect of smoking on the $120 \mathrm{~min}$ value was dose-related since in an earlier study the $2 \mathrm{~h}$ value was found to be inversely related to the concentration of carboxyhaemoglobin [12].

The low $\mathrm{k}$-value in the intravenous GTT in smokers seems incompatible with their low $2 \mathrm{~h}$ value in the oral glucose tolerance test. Since the two test procedures were not performed in the same subjects, we cannot assess whether the low $120 \mathrm{~min}$ value in the oral GTT in smokers was associated with impaired elimination of glucose from plasma. The impaired plasma clearance associated with smoking was strengthened by the even lower k-value in heavy smokers. However, the intermediate $\mathrm{k}$-value in ex-smokers indicated that this influence of smoking was reversible. The impaired elimination of glucose associated with smoking could have many explanations. Some studies have reported lower plasma volumes in smokers than in non-smokers [13]. Since the given amount of glucose in the intravenous GTT was calculated on the basis of body weight and height, this could lead to a higher blood glucose concentration in smokers than in non-smokers. In the present study, however, smokers were found to have significantly lower blood glucose values than non-smokers at $5 \mathrm{~min}$, i. e. at the time when the mixture of glucose and plasma should be complete. One explanation might be the inferred effect of smoking on other hormones. In acute experiments smoking has been found to be associated with increased release of somatotropin [14], thyroid hormones [15] and catecholamines [16] which are known to counteract the effects of insulin on blood glucose.
Several factors are known to have an influence on the oral and intravenous GTT. This study illustrates the significant clinical long term effects associated with smoking. We concluded that smoking habits must be considered when interpreting results from both oral and intravenous glucose tolerance tests.

\section{References}

1. Milson AS (1966) The effect of nicotine on blood glucose levels and plasma non-esterified fatty acid levels in the intact and adrenalectomized rat. Br J Pharmacol 26: 256-259

2. Janzon L, Trell E, Larme P, Lindell S-E, Lindgärde F, Berntorp K, Nordén G, Hood B (1979) Smoking and oral glucose tolerance tests. IRCS Med Sci 7: 514-515

3. Trell E, Janzon L, Berntorp K, Larme P, Thorell J, Lindell S-E, Hood B (1980) Smoking and oral glucose tolerance tests II. Effects on plasma insulin levels. IRCS Med Sci 8: 171-172

4. Trell E, Janzon L, Larme P, Trell J, Lindell S-E, Berntorp K, Hood B (1980) Smoking and intravenous tolerance tests. Effects on $k$ values. IRCS Med Sci 8: 295-296

5. Kristensson H, Trell E, Fex G, Hood B (1980) Serum gammaglutamyltransferase: Statistical distribution in a middle-aged male population and evaluation of alcohol habits in individuals with elevated levels. Prev Med 9: 108-119

6. Lindeberg W, Natvig H, Rygh A, Svendsen K (1956) Height and weight measurements in adult men and women. Tidsk N Laegeforen $76: 361-370$

7. Isaksson SO (1972) Venous occlusion plethysmography in 55-year old men. A population study in Malmö, Sweden. Acta Med Scand Suppl 537

8. Carroll JJ, Smith N, Babson AL (1970) A colorimetric serum glucose determination method using hexokinase and glucose-6-phosphate dehydrogenase. Biochem Med 4: 171-180

9. Heding LF (1966) A simplified insulin radioimmunoassay method. In: Donato L (ed) Label proteins in tracer studies. Euratom, Brussels pp 345-351

10. Schievelbein H (1969) Nikotin-Resorbtion, Stoffwechsel und Ausscheidung. In: Schievelbein H (ed) Nikotin. Pharmakologie und Toxikologie des Tabaksrauches. Thieme, Stuttgart, pp 20-29

11. Report to the Medical Research Council by the Working-Party on the relationship between dietary sugar intake and arterial disease (1970) Dietary sugar intake in men with myocardial infarction. Lancet 2: 1265-1271

12. Janzon L, Trell E, Berntorp K, Thorell J, Lindell S-E, Kristensson $\mathrm{H}$, Hood B (1981) The influence of GTT, $\mathrm{COHb} \%$ and body weight on the 2-h glucose and insulin response after a standardized oral glucose load. Acta Diabet Lat 18: 157-162

13. Smith JR, Lansaw SA (1978) Smokers' polycythemia. New Engl J Med 298: 6-10

14. Sandberg H, Roman L, Zavodnik J, Kupers N (1973) The effect of smoking on serum somatotropin, immunoreactive insulin and blood glucose levels of young adult males. J Pharmacol Exp Ther 184: 787-791

15. Melander A, Nordenskjöld E, Lundh B, Thorell J (1981) Influence of smoking on thyroid activity. Acta Med Scand 209: 41-45

16. Armitage AK (1965) Effects of nicotine and tobacco smoke on blood pressure and release of catecholamines from the adrenal glands. Br J Pharmacol 25: 515-526

Received: 30 September 1982

and in revised form: 1 June 1983

Dr. L. Janzon

Department of Surgery

University of Lund

Malmö General Hospital

S-21401 Malmö

Sweden 